\title{
Stomal Ulcer, CTCAE 5.0
}

National Cancer Institute

\section{Source}

National Cancer Institute. Stomal UIcer, CT CAE 5.0. NCI Thesaurus. Code C146694.

A disorder characterized by a circumscribed, erosive lesion on the jejunal mucosal surface close to the anastomosis site following a gastroenterostomy procedure. 